\title{
Molecular Docking Studies of Curcumin Derivatives with Multiple Protein Targets for Procarcinogen Activating Enzyme Inhibition
}

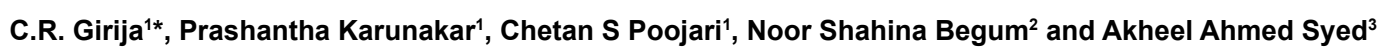

${ }^{1}$ Department of Chemistry, SSMRV College, $4^{\text {th }} T$ Block, Jayanagar, Bangalore-560041, India

${ }^{2}$ Department of Studies in Chemistry, Bangalore University, Central College Campus, Bangalore-560001, India

${ }^{3}$ Department of Studies in Chemistry, University of Mysore, Manasagangothri, Mysore-570006, India

\begin{abstract}
Curcumin derivatives which are very potent antioxidant, free radical scavenger and known inhibitor of dioxygenases have been extensively studied to explore their potential utilization in chemoprevention. The main objective of the present work is to perform a docking analysis of curcumin derivatives: Tetrahydrocurcumin (THC), Bisdemethoxy curcumin (BDC). Docking studies of these were performed using GOLD and AutoDock into a few well validated targets of anticancer therapy (COX-2, PhenolsulphoTransferases, Matrix metalloproteinases (MMPs), P450 and TNF-alpha). A good correlation was observed in binding affinity of THC and BDC against the targets indicating these derivatives are potent procarcinogen activating enzyme inhibitors.
\end{abstract}

Keywords: Docking; Procarcinogen inhibitors; Anticancer therapy targets; Tetrahydrocurcumin; Bisdemethoxycurcumin

\section{Introduction}

Curcumin [1,7-bis (4-hydroxy-3-methoxyphenyl)-1, 6-heptadiene3,5-Dione] is the major component of the Curcumin species used as a yellow coloring and flavoring agent in foods. Curcumin has shown anti-carcinogenic activity in animals as indicated by its ability to block colon tumor initiation by azoxymethane and skin tumor promotion induced by phorbol ester TPA. It is proposed that curcumin may suppress tumor promotion by blocking signal transduction pathways in the target cells (Lin and Lin-Shiau, 2001). Curcumin has been demonstrated to have potent antioxidant (Kunchandy and Rao, 1990; Subramanian et al., 1994; Sreejayan and Rao, 1994), anti-inflammatory activity (Huang et al., 1988; Conney et al., 1991; Huang et al., 1997; Liu et al., 1993), to inhibit the carcinogen-DNA adduct (Conney et al., 1991) and tumorigenesis in several animal models (Huang et al., 1992; Huang et al., 1994; Huang et al., 1995; Rao et al., 1995).

As a part of our continuing program to discover procarcinogen inhibitory compounds, curcumin derivatives were studied. Tetrahydrocurcumin(THC) and bisdemethoxycurcumin(BDC) Figure 1 , are the reduced form of curcumin, derived from curcuminoids and can also be extracted from the roots of Curcuma longa, commonly called turmeric root (Govindarajan, 1980). Tetrahydrocurcuminoids are colorless unlike bisdemethoxycurcumin an yellow curcuminoid which are used in color-free foods and cosmetic products. An antioxidant used in a cosmetic application should have the capability of efficiently quenching any radicals on the surface of the skin. In this context, compound THC displays superior free-radical scavenging ability and also exhibits antioxidant, anti-inflammatory and skinlightening actions (Sugiyama et al., 1996; Rao et al., 1982) and anticancer activity (Huang et al., 1995). It is thought that the $p$-hydroxy functional groups in THC are responsible for the antioxidant activity and keto groups are responsible for the chemopreventive action of the compound (Rao et al., 1995; Halliwell and Gutteridge, 1985). The crystal structures (Figure 2a and Figure 2b) of THC abd BDC have been determined using X-ray crystallography and the results have been extrapolated for docking analysis (Girija et al., 2004).

The concept of docking is important in the study of various properties associated with protein-ligand interactions such as binding energy, geometry complementarity, electron distribution, hydrogen bond donor acceptor properties, hydrophobicity and polarizability. Since molecules in nature have a tendency to be found in their low energy form, the final configuration should also be of low energy (Pyne and Gayathri, 2005). Understanding these properties is crucial in rationale design of potent inhibitors.
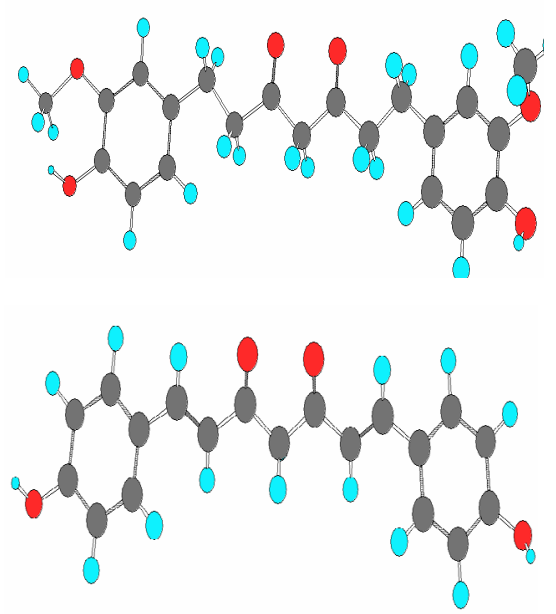

Figure 1: Structure of $\mathrm{THC}$ and $\mathrm{BDC}$ as viewed in Chem3D Ultra with atom coloring.

*Corresponding author: C.R. Girija, Department of Chemistry, SSMRV College 4th T Block, Jayanagar, Bangalore-560041, India, Tel: +91 98864 19952; E-mail: girijashivakumar@rediffmail.com

Received May 25, 2010; Accepted June 26, 2010; Published June 26, 2010

Citation: Girija CR, Karunakar P, Poojari CS, Begum NS, Syed AA (2010) Molecular Docking Studies of Curcumin Derivatives with Multiple Protein Targets for Procarcinogen Activating Enzyme Inhibition. J Proteomics Bioinform 3: 200 203. doi:10.4172/jpb.1000140

Copyright: @ 2010 Girija CR, et al. This is an open-access article distributed unde the terms of the Creative Commons Attribution License, which permits unrestricted use, distribution, and reproduction in any medium, provided the original author and source are credited. 

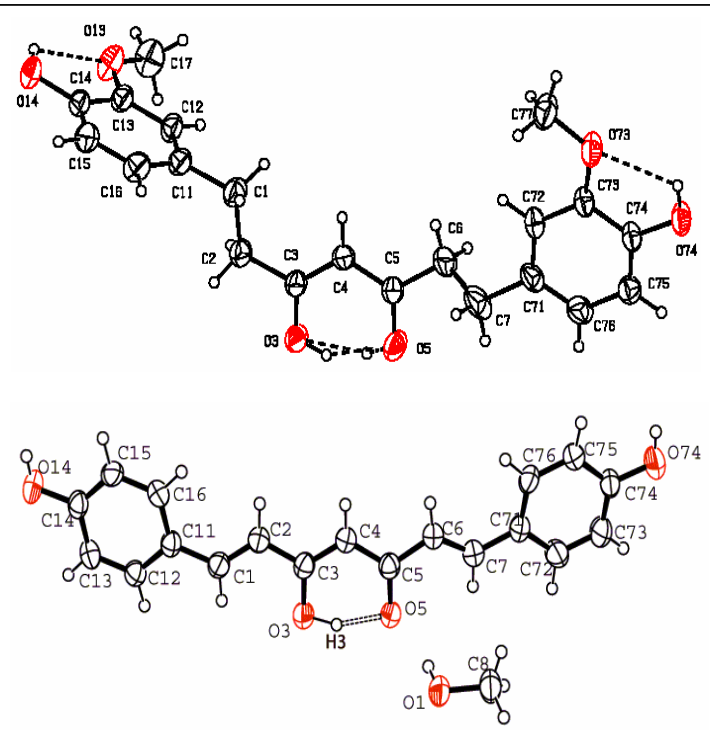

Figure 2a: The structures of the compounds THC and BDC showing 50\% probability displacement ellipsoids and the atom numbering scheme.

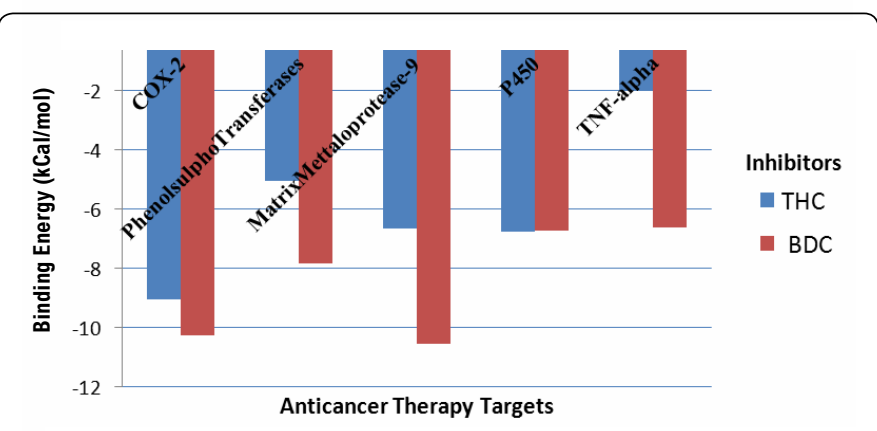

Figure 2b: Comparison in Binding Energy of THC and BDC using AutoDock 3.0.

\section{Materials and Methods}

\section{Preparation of ligand structures}

The small-molecule topology generator Dundee PRODRG 2 server (Schuttelkopf and van Aalten, 2004) is used for ligand optimization, a tool for high-throughput crystallography of protein-ligand complexes which takes input from existing coordinates or various two-dimensional formats and automatically generates coordinates and molecular topologies suitable for X-ray refinement of proteinligand complexes. CambridgeSoft-ChemOffice 6.0.1(CambridgeSoft. com, Cambridge, MA, USA) tool used for physicochemical properties of THC and BDC (Table 1).

\section{Preparation of protein structures}

Availability of several experimentally determined threedimensional structures of COX-2 (1PXX), Phenol sulpho Transferases (1LS6), Matrix metalloproteinases (MMPs) (1GKC), P450 (10G5) and TNF-alpha (1A8M) co crystallized with various inhibitors provides an excellent basics for using structure-based approaches for the discovery of new inhibitors. All water molecules and if present, ligands were removed from the proteins for docking studies.

\section{Protein-ligand interaction using autodock and GOLD}

Autodock (version 3.0): AutoDock 3.0 includes Lamarckian Genetic Algorithm search engine and an empirical free energy function for estimating binding energy, docking energy, inhibitory constant, intermolecular energy, torsional energy and internal energy. Four binding energy terms were included in the score function: electrostatic, van der wall, hydrogen bonding and desolvaion effect. The binding free energy is empirically calculated based on these energy terms and a set of co-efficient factors (Morris et al., 1998).

Using MGLTools 1.5.1, a grid spacing of $0.374 \AA$ 我 with 60x60x60 points for all Proteins was prepared. The grid was centered around the catalytic clef of the enzyme for docking. Docking for 100 number of GA run was carried out using Lamarckian Genetic Algorithm (LGA) and all other parameters set to default. The top ranked model in the lowest energy cluster with maximum cluster size was considered for all further interaction studies.

GOLD (version 2.1.2): GOLD, which is available through the Cambridge Crystallographic Data Center (CCDC) utilizes a genetic algorithm that was originally described by Jones and colleagues and an evolutionary strategy involving three genetic operators; crossover, mutation and migration (Jones et al., 1997; Jones et al., 1995). It was the first algorithm to be evaluated on a large dataset of complexes, possesses an empirical free energy scoring function that estimates the free energy of binding permitting inhibition constants, $K i$ to be calculated. Although initial applications of GOLD and the GA employed provided poor convergence results for hydrophobic ligands, It has recently been validated using a test set of 305 diverse protein-ligand complexes and $72 \%$ of the top-ranked solutions were deemed accurate using the authors' self-imposed stringent success criteria (Nissink et al., 2002).

\section{Results and Discussion}

In assessment using AutoDock 3.0, BDC showed better affinity with all anticancer therapy targets than THC. Interaction of BDC with respect to Matrix Mettaloprotease (MMPs) is represented. A docking energy of $-11.46 \mathrm{Kcal} / \mathrm{mol}$ with three hydrogen bonds was
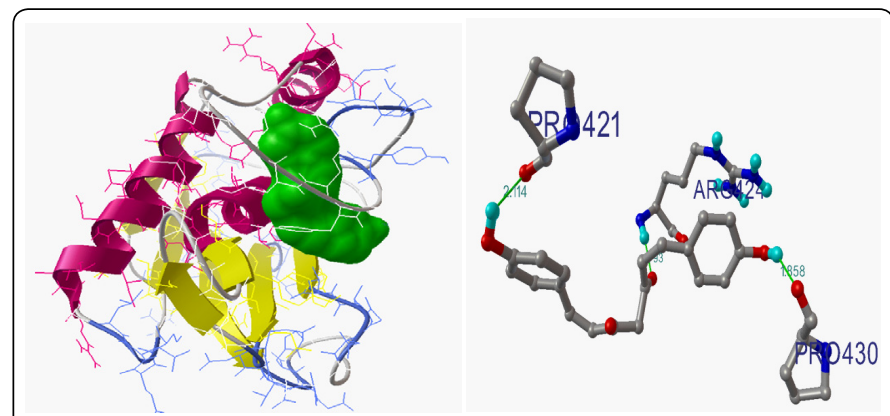

Figure 3a: Binding mode of BDC (shown in Green Molecular Surface model) to MMPs (Left). Binding mode of BDC in the active site (top view) of MMPs along with interacting amino acids(Right) from their respective regions of active site.

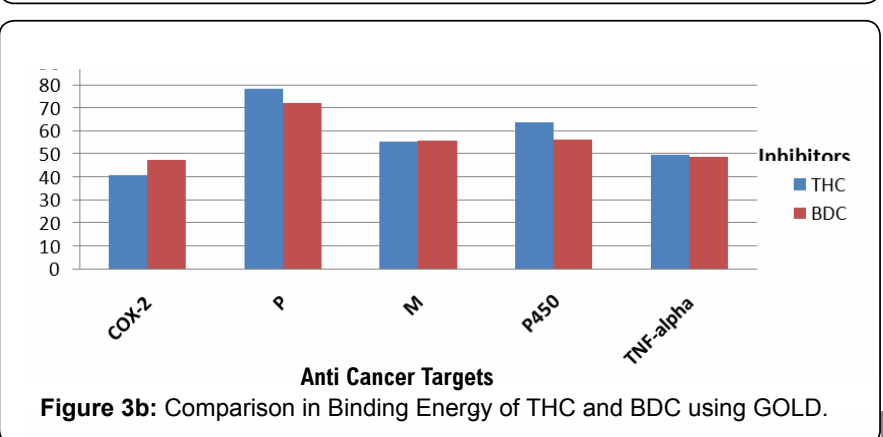




\begin{tabular}{|c|c|c|}
\hline Physicochemical Properties & Tetrahydrocurcumin & Bisdemethoxycurcumin \\
\hline Boiling Point & $787.355 \mathrm{~K}$ & $747.197 \mathrm{~K}$ \\
\hline Melting Point & $771.57 \mathrm{~K}$ & $669.37 \mathrm{~K}$ \\
\hline Critical Volume & $1075.5 \mathrm{Cm} . \mathrm{Cm} . \mathrm{Cm} / \mathrm{mol}$ & $887.5 \mathrm{Cm} . \mathrm{Cm} . \mathrm{Cm} / \mathrm{mol}$ \\
\hline Critical Temperature & $969.303 \mathrm{~K}$ & $946.4 \mathrm{~K}$ \\
\hline Critical Pressure & 20.437 Bar & 29.155 Bar \\
\hline \multicolumn{3}{|c|}{ Crippens fragmentation method ( Crippens, 1987) } \\
\hline $\log (P)$ & 2.60 & 2.81 \\
\hline Molar Refractivity & $102.09 \mathrm{Cm} . \mathrm{Cm} . \mathrm{Cm} / \mathrm{mol}$ & $91.30 \mathrm{Cm} . \mathrm{Cm} . \mathrm{Cm} / \mathrm{mol}$ \\
\hline Heat of Formation & $-870.87 \mathrm{KJ} / \mathrm{mol}$ & $-307.77 \mathrm{KJ} / \mathrm{mol}$ \\
\hline Gibbs Energy & $-445.58 \mathrm{KJ} / \mathrm{mol}$ & $-72.72 \mathrm{KJ} / \mathrm{mol}$ \\
\hline Ideal gas thermal capacity & $438.08 \mathrm{~J} / \mathrm{mol} . \mathrm{K}$ & $329.49 \mathrm{~J} / \mathrm{mol} . \mathrm{K}$ \\
\hline Henry's Law constant & $18.2264 \log$ & $17.0884 \log$ \\
\hline Connolly Accessible Area & $662.529(\AA)$ squared & $574.346(\AA)$ squared \\
\hline Connolly Molecular Area & $360.435(\AA)$ squared & $301.153(\AA)$ squared \\
\hline Connolly Solvent-Excluded Area & $307.909(\AA)$ cubed & $244.895(\AA)$ cubed \\
\hline Molecular Formula & $\mathrm{C}_{21} \mathrm{H}_{24} \mathrm{O}_{6}$ & $\mathrm{C}_{19} \mathrm{H}_{16} \mathrm{O}_{4}$ \\
\hline Molecular Weight & 372.41 a.m.u & 308.33 a.m.u \\
\hline Bend Energy & $17.923 \mathrm{Kcal} / \mathrm{mol}$ & $8.163 \mathrm{Kcal} / \mathrm{mol}$ \\
\hline Dipole-Dipole Energy & $6.239 \mathrm{Kcal} / \mathrm{mol}$ & $6.538 \mathrm{Kcal} / \mathrm{mol}$ \\
\hline Non-1, 4 VDW Energy & $8.751 \mathrm{Kcal} / \mathrm{mol}$ & $1.065 \mathrm{Kcal} / \mathrm{mol}$ \\
\hline Stretch Energy & $5.041 \mathrm{Kcal} / \mathrm{mol}$ & $7.567 \mathrm{Kcal} / \mathrm{mol}$ \\
\hline Stretch-Bend- Energy & $-0.333 \mathrm{Kcal} / \mathrm{mol}$ & $-0.129 \mathrm{Kcal} / \mathrm{mol}$ \\
\hline Torsion Energy & $-6.825 \mathrm{Kcal} / \mathrm{mol}$ & $-8.912 \mathrm{Kcal} / \mathrm{mol}$ \\
\hline 1, 4 VDW Energy & $19.458 \mathrm{Kcal} / \mathrm{mol}$ & $9.283 \mathrm{Kcal} / \mathrm{mol}$ \\
\hline
\end{tabular}

Table 1: Physicochemical properties of THC and BDC

showed. The hydrogen bond was formed between hydroxyl (H14) of the phenyl ring and carboxyl $(\mathrm{O})$ of hydrophobic amino acid Pro421 by a distance of $2.114 \AA(\mathrm{O}-\mathrm{H}$. . . O ) and energy of $-0.374 \mathrm{Kcal} / \mathrm{mol}$. Another interaction bridging (O5) of the heptane branch and amine (NH2) of positively charged residue Arg424 with a distance of 1.793 $\AA(\mathrm{N}-\mathrm{H}$. . . O) along a minimum energy of $-5.492 \mathrm{Kcal} / \mathrm{mol}$. The hydroxyl (H74) of another phenyl ring and carboxyl $(\mathrm{O})$ of hydrophobic amino acid Pro 430 by a distance of $1.858 \AA(\mathrm{O}-\mathrm{H}$. . .O) along with a energy of-1.817 Kcal/mol (Figure 3a).

From GOLD also it was observed that BDC showed better affinity with COX-2 and Matrix Mettaloprotease (MMPs) than Phenol sulpho transferases, P450, TNF-alpha anticancer therapy targets though THC showed good affinity to Phenol sulpho transferases, P450 and TNFalpha (Figure 3b).

\section{Conclusion}

Analysis of these docked ligands with the proteins brought in focus some important interactions operating at the molecular level. The six-membered phenyl ring plays a vital role in holding the molecule at place (binding) at the active site by three important hydrogen bonds. The present study also attempts a 3D-QSAR study on curcumin derivatives. Applying Lipinski's Rule of five to curcumin derivatives to evaluate druglikeness (absorption,distribu tion,metabolism and excretion), there was no violation of the rule determining drugs pharmacological activity in the body. These studies are expected to provide useful insights into the roles of various substitution patterns on the curcumin derivative and also help to design more potent compounds. The docking studies and 3D-QSAR indicate that substitution of electron-rich compounds may lead to improved biological activity of curcumin derivatives. Thus this study will be useful for the design of novel procarcinogen activating enzyme inhibitors based on docking methods.

\section{Acknowledgement}

CRG and PK thank RSST and Principal SSMRV Degree College for their encouragement and support.

\section{References}

1. Conney AH, Lysz T, Ferraro T, Abidi TF, Manchand PS, et al. (1991) Inhibitory effect of curcumin and some related dietary compounds on tumor promotion and arachidonic acid metabolism in mouse skin. Adv Enzyme Regul 31: 385396.

2. Ghose AK, Crippen GM (1987) Atomic physicochemical parameters for threedimensional-structure-directed quantitative structure-activity relationships. 2 Modeling dispersive and hydrophobic interactions. J Chem Inf Comput Sci 27: 21-35.

3. Girija CR, Begum NS, Syed AA, Thiruvenkatam V (2004) Hydrogen-boding and $\mathrm{C}-\mathrm{H} . . . \pi$ interactions in 1,7-bis(4-hydroxy-3-methoxyphenyl)hepatne-3,5dione(tetrahydrocurcumin). Acta Crystallogr C 60: o611-o613.

4. Govindarajan VS (1980) Turmeric--chemistry, technology, and quality. Crit Rev Food Sci Nutr 12: 199-301.

5. Halliwell B, Gutteridge John MC (1985) Oxygen radicals and the nervous system. Trends Neurosci 8: 22-26.

6. Huang MT, Lou YR, Ma W, Newmark HL, Reuhl KR, et al. (1994) Inhibitory effects of dietary curcumin on forestomach, duodenal, and colon carcinogenesis in mice. Cancer Res 54: 5841-5847.

7. Huang MT, Ma W, Lu YP, Chang RL, Fischer C, et al. (1995) Effects of curcumin demethoxycurcumin, bisdemethoxycurcumin and tetrahydrocurcumin on 12-O-tetradecanoylphorbol-13-acetate-induced tumor promotion Carcinogenesis 16: 2493-2497.

8. Huang MT, Ma W, Yen P, Xie JG, Han J, et al. (1997) Inhibitory effects of topical application of low doses of curcumin on 12-O-tetradecanoylphorbol-13acetate-induced tumor promotion and oxidized DNA bases in mouse epidermis. Carcinogenesis 18: 83-88.

9. Huang MT, Smart RC, Wong CQ, Conney AH (1988) Inhibitory effect of curcumin, chlorogenic acid, caffeic acid, and ferulic acid on tumor promotion in mouse skin by 12-O-tetradecanoylphorbol-13-acetate. Cancer Res 48: 59415946.

10. Huang MT, Wang ZY, Georgiadis CA, Laskin JD, Conney AH (1992) Inhibitory effect of curcumin on tumor initiation by benzo[a] pyrene and 7,12-dimethylbenz[a]anthracene. Carcinogenesis 13: 2183-2186.

11. Jones G, Willett P, Glen RC (1995) Molecular recognition of receptor sites using a genetic algorithm with a description of desolvation. J Mol Biol 245: 43-53.

12. Jones G, Willett P, Glen RC, Leach AR, Taylor R (1997) Development and validation of a genetic algorithm for flexible docking. J Mol Biol 267: 727-748.

13. Kunchandy E, Rao MNA (1990) Oxygen radical scavenging activity of curcumin Int J Pharm 58: 237-240.

14. Lin JK, Lin-Shiau SY (2001) Mechanisms of Cancer Chemoprevention by Curcumin. Proc Natl Sci Counc Repub China B 25: 59-66.

15. Liu JY, Lin SJ, Lin JK (1993) Inhibitory effects of curcumin on protein kinase $\mathrm{C}$ activity induced by 12-O-tetradecanoyl-phorbol-13-acetate in NIH 3T3 cells. Carcinogenesis 14: 857-861. 
Citation: Girija CR, Karunakar P, Poojari CS, Begum NS, Syed AA (2010) Molecular Docking Studies of Curcumin Derivatives with Multiple Protein Targets for Procarcinogen Activating Enzyme Inhibition. J Proteomics Bioinform 3: 200-203. doi:10.4172/jpb.1000140

16. Morris GM, Goodsell DS, Halliday RS, Huey R, Hart WE, et al. (1998) Automated docking using a Lamarckian genetic algorithm and an empirical binding free energy function. J Comput Chem 19: 1639-1662.

17. Nissink JW, Murray C, Hartshorn M, Verdonk ML, Cole JC, et al. (2002) A new test set for validating predictions of protein-ligand interaction. Proteins 49: 457471.

18. Pyne S, Gayathri P (2005) Geometric Methods in Molecular Docking. Bioinformatics India Journal III: 11-12.

19. Rao CV, Rivenson A, Simi B, Reddy BS (1995) Chemoprevention of Colon carcinogenesis by dietary curcumin, a naturally occurring plant phenolic compound. Cancer Res 55: 259-266.

20. Rao TS, Basu N, Siddique HH (1982) Anti-Inflammatory Activity of Curcumin Analogues. Indian J Med Res 75: 574-578.
21. Schuttelkopf AW, van Aalten DM (2004) PRODRG: a tool for high-throughput crystallography of protein-ligand complexes. Acta Crystallogr D Biol Crystallogr 60: $1355-1363$.

22. Sreejayan N, Rao MN (1994) Curcuminoids as potent inhibitors of lipid peroxidation. J Pharm Pharmacol 46: 1013-1016.

23. Subramanian M, Sreejayan, Rao MN, Devasagyam TP, Singh BB (1994) Diminution of singlet oxygen-induced DNA damage by curcumin and related antioxidants. Mutat Res 311: 249-255.

24. Sugiyama Y, Kawakishi S, Osawa T (1996) Involvement of the $\beta$-diketone moiety in the antioxidative mechanism of tetrahydrocurcumin. Biochem Pharmacol 52: 519-525.

25. Tonnesen HH, Karlsen J (1983) High-performance liquid chromatography of curcumin and related compounds. J Chromatogr 259: 367-371. 